and Company, Galderma, Janssen, Merck, Novartis, Pfizer, LEO Pharma, Sandoz, Stiefel, UCB, Pfizer, Vitae, and Wyeth, Consultant for: AbbVie, Actavis, Amgen, Boehringer Ingelheim, Celgene, Coherus, Corrona, Dermira, Janssen, Eli Lilly and Company, Galderma, Janssen, Merck, Novartis, Pfizer, LEO Pharma, Sandoz, Stiefel, UCB, Pfizer, Vitae, and Wyeth, Speakers bureau: AbbVie, Actavis, Amgen, Boehringer Ingelheim, Celgene, Coherus, Corrona, Dermira, Janssen, Eli Lilly and Company, Galderma, Janssen, Merck, Novartis, Pfizer, LEO Pharma, Sandoz, Stiefel, UCB, Pfizer, Vitae, and Wyeth, S. Sturgill-Koszycki Employee of: Former employee of Sun Pharmaceutical Industries, Inc., A. Menter Grant/research support from: AbbVie, Allergan, Amgen, Anacor Boehringer Ingelheim, Celgene, Dermira, Eli-Lilly, Galderma, Janssen Biotech, Inc. LEO Pharma, Merck, Neothetics, Novartis, Pfizer, Regeneron, Symbio/Maruho, Xenoport, Consultant for: AbbVie Allergan Amgen Eli-Lilly Galderma Janssen Biotech, Inc LEO Pharma Novartis Pfizer Vitae Xenoport, Speakers bureau: AbbVie, Amgen, Janssen Biotech, Inc LEO Pharma, A. Mendelsohn Employee of: Sun Pharmaceutical Industries, Inc., Q. Li Employee of: Merck Sharp and Dohme Corp., a subsidiary of Merck and Co., Inc., Kenilworth, NJ, USA, N. Cichanowitz Shareholder of: Merck and Co., Inc., Employee of: Merck Sharp and Dohme Corp., a subsidiary of Merck and Co., Inc., Kenilworth, NJ, USA, C. La Rosa Employee of: Merck Sharp and Dohme Corp., a subsidiary of Merck and Co., Inc., Kenilworth, NJ, USA DOI: 10.1136/annrheumdis-2018-eular.6730

\section{SAT0313 LIPID PROFILE OF PSORIATIC ARTHRITIS PATIENTS. A FIVE-YEAR STUDY}

M. Migkos, E. Kaltsonoudis, T.E. Markatseli, A.A. Drosos, P.V. Voulgari. Rheumatology Clinic, Department Of Internal Medicine, Medical School, University Of Ioannina, Ioannina, Greece

Background: Psoriatic arthritis (PsA) is an inflammatory arthritis associated with psoriasis. Many studies have shown alterations in lipid profile of PsA patients and an association with increased cardiovascular risk.

Objectives: To evaluate the changes of lipid profile in PsA patients treated with conventional synthetic disease modifying anti-rheumatic drugs (csDMARDs) and/ or with biological DMARDs (bDMARDs) in a five-year period.

Methods: We studied 254 patients diagnosed with PsA according to CASPAR and ASAS (for those with axial disease) criteria. Patients were followed up at predefined time points [baseline, 24 weeks (wks), 48 and 240 wks after initiation of treatment. We recorded levels of Total Cholesterol (CHOL), Low Density Lipoproteins (LDL), High Density Lipoproteins (HDL) and Triglycerides (TGL). The disease activity was assessed by using Bath Ankylosing Spondylitis Disease Activity Index (BASDAI), Bath Ankylosing Spondylitis Functional Index (BASFI), disease activity score-28 (DAS) -C-Reactive Protein (CRP), DAS28-erythrocyte sedimentation rate (ESR), Health Assessment Questionnaire (HAQ), and inflammatory marker CRP and ESR. Patients were categorised in three treatment groups: patients treated with bDMARDs: anti-tumour necrosis factor alpha (TNFa) agents, patients treated with csDMARDs and combined therapy (bDMARDs and csDMARDs). Disease Phenotype and epidemiological features of PsA patients were also recorded.

Results: There were 137 male and 117 female patients. The (Mean $\pm S D)$ age of the patients was $56,11 \pm 14,64$ years and the body mass index (BMI) was 27,86 $\pm 5,12$. Thirty-nine per cent of the patients presented as asymmetric oligoarthritis, $25,6 \%$ as symmetric polyarthritis while $27,6 \%$ had axial involvement with or without peripheral arthritis. Total $\mathrm{CHOL}$ and LDL levels were significantly associated with disease duration $(p<0,05)$ while TGL and HDL were not significantly correlated. We found that HDL levels were significantly correlated with disease activity through time. More specific lower disease activity was associated with higher HDL levels for all disease activity scores and CRP at all time points $(p<0,05)$. The significance was lost only for ESR. No association was found between the HDL levels and the different therapeutic option used. The rest of lipid profile levels did not show statistical significant association with disease activity at any time point for all disease activity indexes, including CRP and ESR.

Conclusions: Lipid profile of PsA patients seems to improve with better control of disease activity. More specifically high HDL levels are associated with low disease activity and these changes appear to be independent of the therapeutic choices.

Disclosure of Interest: None declared

DOI: 10.1136/annrheumdis-2018-eular.5264

\section{SAT0314 \\ TO DESCRIBE AND CHARACTERISE THE PATIENT GROUP DEFINED AS COMPLEX IN A JOINT} RHEUMATOLOGY/DERMATOLOGY CLINIC (PAIDER)

A. Garcia-Guillen ${ }^{1}$, A. Laiz ${ }^{1}$, A. Lopez-Ferrer ${ }^{2}$, P. Moya ${ }^{1}$, I. Castellví1, B. Magallares ${ }^{1}$, C. Diaz-Torné ${ }^{1}$, H. Corominas ${ }^{1}$, H. Park ${ }^{1} .{ }^{1}$ Rheumatology;

${ }^{2}$ Dermatology, Hospital de la Santa Creu i Sant Pau, Barcelona, Spain

Objectives: To describe and characterise the patient group defined as complex in a joint Rheumatology/Dermatology clinic (PAIDER).

Methods: We performed a retrospective chart review of patients evaluated between May 2012 and November 2017 at a weekly joint Rheumatology/Dermatology clinic at Hospital de Sant Pau (Autonomous University of Barcelona), Spain. We reviewed the medical records for demographic information, source of referral, complexity, cardiovascular risk factors and the number of visits. Complexity or complex patient was defined by at least one of the following characteristics: liver disease, neoplastic disease, psychiatric disorders, communication difficulties, adverse drug reactions to previous treatment, or paradoxical effects of biological therapy. The degree of complexity was a number (from 1 to 6 ) resulting from the sum of the previous characteristics. A descriptive analysis was carried out and the correlation between variables was studied through the application of nonparametric tests. The statistical package SPSS v. 21 was used to analyse the data. Results: 494 patients were evaluated (52\% women) with a total of 1110 visits The mean age was 53 years. Patients were referred from Rheumatology, Dermatology, primary care physicians and other specialties in $47 \%, 40 \%, 6.5 \%$ and $5.5 \%$ of cases, respectively. The average number of visits per patient was 2.25 . 164 patients (33\%) were defined as complex with a total of 546 visits. $48.8 \%$ were women. The mean age was 55 years. They were referred from Rheumatology, Dermatology, primary care physicians and other specialties in $50.6 \%, 35.4 \%$, $7.3 \%$ and $6.7 \%$ of cases, respectively. The mean number of following-up visits for the complex patients was 3.33 .

The features that defined complexity and the number of visits required are shown in table 1

\begin{tabular}{lcc}
\hline Complexity features & Number of patients & $\begin{array}{c}\text { Visits } \\
\text { Mean } \pm \text { SD }\end{array}$ \\
\hline Liver disease & $47 / 164(28.7 \%)$ & $3.6 \pm 3.7$ \\
Psychiatric disorder & $47 / 164(28.7 \%)$ & $3.4 \pm 4.7$ \\
Adverse drug reactions & $46 / 164(28 \%)$ & $4.7 \pm 5.2$ \\
Paradoxical effects of biological therapy & $37 / 164(22.6 \%)$ & $5.2 \pm 5.7$ \\
Neoplastic disease & $27 / 164(16.5 \%)$ & $1.8 \pm 1.5$ \\
Communication difficulties & $19 / 164(11.6 \%)$ & $4.1 \pm 4.9$ \\
\hline
\end{tabular}

The number of visits according to the degree of complexity is shown in table 2.

\begin{tabular}{lcc}
\hline Degree of complexity & Number of patients & $\begin{array}{c}\text { Visits } \\
\text { Mean } \pm \text { SD }\end{array}$ \\
\hline 1 & $120 / 164(73.2 \%)$ & $2.8 \pm 2.9$ \\
2 & $32 / 164(19.5 \%)$ & $4.1 \pm 4.1$ \\
3 & $10 / 164(6.1 \%)$ & $6.4 \pm 7.3$ \\
4 & $1 / 164(0.6 \%)$ & 1 \\
5 & $1 / 164(0.6 \%)$ & 1 \\
6 & $0 / 164(0 \%)$ & 0 \\
\hline
\end{tabular}

The complexity features that had a significant correlation with the number of visits were liver disease $(p<0.001)$, serious adverse effects to previous treatments $(p<0.001)$ and paradoxica effects of biological therapy $(p<0.001)$. The degree of complexity was also correlated with the number of visits (Spearman's Rho $=0.262, \mathrm{p}<0.001$ )

Conclusions: A third of the patients visited in our joint clinic were defined as complex, although the great majority showed a low level of complexity. Of all the features used to define complexity, only a few were associated with a greater numbe of visits. However, the degree of complexity of the patients was associated with an increased number of visits.

Disclosure of Interest: None declared

DOI: 10.1136/annrheumdis-2018-eular.7056 